\title{
Discovery anti-diabetic potent ofthiazolidinedione derivative based on virtual screening against aldose reducates.
}

\section{A.A.Elhenawy ${ }^{1,2^{*}}$, Mahmoud M. Abdel All ${ }^{1,2}$ and Abd aziz A. Alomri ${ }^{1}$}

${ }^{1}$ Chemistry Department, Faculty of Arts\& Science, Albaha University, AlBaha, KSA

${ }^{2}$ Chemistry Department, Faculty of Science, Al-Azhar University, Nasr City,Cairo, Egypt

Address correspondence to A. A. Elhenawy; Email: Elhenawy_sci@hotmail. Com.

\begin{abstract}
Thiazolidinedione (1) was used as a key intermediate for the synthesis of many therapeutic anti-diabetic molecules. Thus, Thiazolidinedione (1) was refluxed with aromatic aldehydes and phenol derivatives to afforded aryldine derivative (3). Moreover, the stereochemistry for compound 3 was discussed using Hartree-Fock theory geometries,and have been optimized at HF with 6-311G level of theory. The HOMO-LUMO energy gap of studied systems has been discussed. The molecular docking simulations into the active site of ALR2 were performed, and showed that, the compound 3more suitable inhibitor against ALR2 and can used as anti- diabetic drug.
\end{abstract}

Keywords: Antidibeatic; ADMET; ALR2 and Thiazolidinediones

\section{Council for Innovative Research}

Peer Review Research Publishing System

Journal: Journal of Advances in Chemistry

Vol. 10, No. 4

editorjaconline@gmail.com

www.cirjac.com 


\section{Introduction}

Diabetes mellitus (DM) is a common chronic, more than 220 million people worldwide suffer from DM, this figure is expected to increase by 2030 to 400 million cases [1,2]. Diabetic complications (retinopathy, neuropathy, nephropathy or cataract) are serious and disabling pathologies associated with DM[3]. Hyperglycemia is a typical condition of DM and plays a crucial role in the development and advancement of these complications, which arise from acute, and are thus largely responsible for the morbidity and mortality observed in these patients[1, 4-6].

Increasing flux of glucose through the polyol pathway, that occurs under hyperglycemic conditions in tissues possessing insulin-independent glucose transport is a well examined factor involved in the appearance and progression of such chronic complications[ 3,6-13]. Aldose reductase (EC 1.1.1.21, ALR2) is the first enzyme of the polyol pathway, which responsible for reduction of glucose to sorbitol[14]. Glucose metabolism, specifically via ALR2 and the polyol pathway, is often linked to the development of chronic complications of diabetes mellitus. Therefore, ALR2 has been considered an attractive target enzyme, to develop drugs to control or prevent the progression of chronic diabetic complications, but remain many problems with toxicity and lack of targeted specificity towards the enzyme[11,13-16].

Many thiazolidinediones derivatives have been marketed for the treatment of non-insulin-dependent diabetes mellitus (NIDDM or type 2 diabetes) [17-,23], such as pioglitazone, rosiglitazone and troglitazone (Structure 1). Thiazolidinediones (TZDs), playing effective role in normalizing glucose metabolism associated with insulin resistance, so, TZDs are considering antidiabetic agents [21]<smiles>CCc1ccc(CCOc2ccc(CC3SC(=O)NC3=O)cc2)nc1</smiles>

In view of the above mentioned, we discovery potent the synthetic thiazldinone derivatives against diabetic II, though, docking studies against ALR-2 to gain a new insight concerning possible binding modes of our compounds, which should also be useful to guide improved potency compounds against diabetic disease .

\section{Results and Discussion}

\subsection{Chemistry}

2,4-Thiazolidinedione(1) was used as our starting material. The compound (1)was treatment with phenol in ethanolic AcONa toaffording unexpected product 5-(benzo[d][1,3]dioxol-5-ylmethylene)-thiazolidine-2,4-dione (3) insteadof 5(benzo[d][1,3]dioxol-5-yl(4-hydroxyphenyl)-methyl)thiazolidine-2,4-dione (2;Scheme 1).

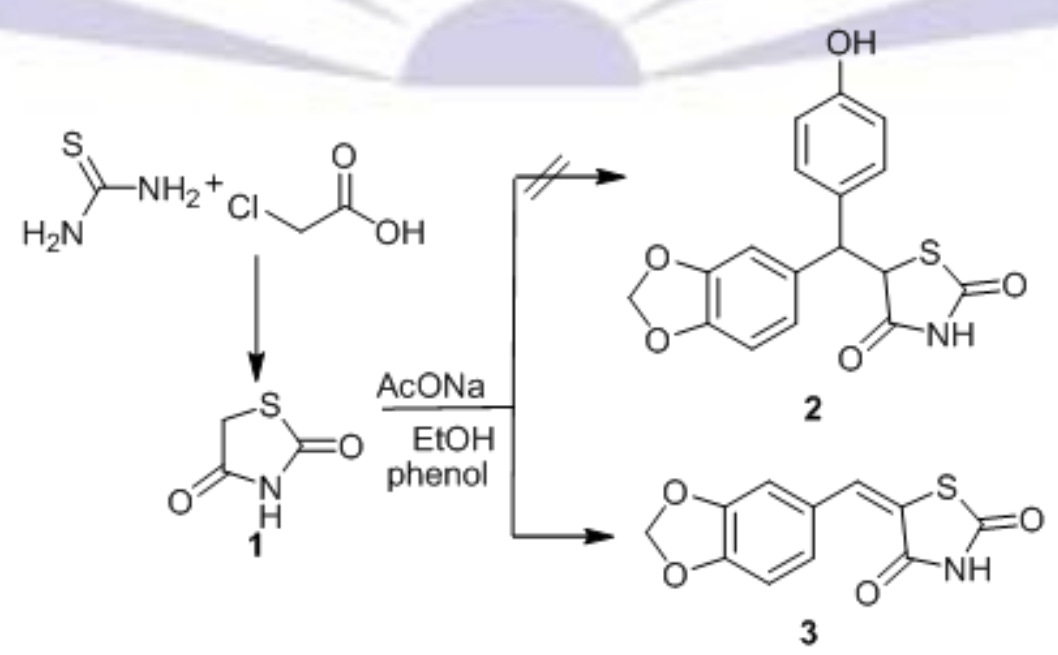

Scheme 1 


\subsection{Molecular Modeling Studies:}

\subsubsection{Energy features}

Due to the presence double bond (represented *),the prepared compound 3is possible existence in two steroisomer forms $\boldsymbol{E}$ and $\boldsymbol{Z}$ (Scheme 2). The appearance $\mathrm{NH}$ fragment in thiazldinone ring, the prepared compoundhavetwo possible tautomerstructures (keto-form) form, which represented in (Scheme 3), the geometrical optimization of both tautomerstructures represented in (Scheme 3).

The molecular parameters and geometry optimization structures were calculated at HF with 6-311 basis set using gaussian 09[24], andused to investigate the most stable steroisomerand tautomer form for compound3(Table 1, scheme 2 and 3 ).<smiles>C=C=C=C</smiles>

$(E)$<smiles>O=C1NC(=O)C(=Cc2ccc3c(c2)OCO3)S1</smiles>

(Z)

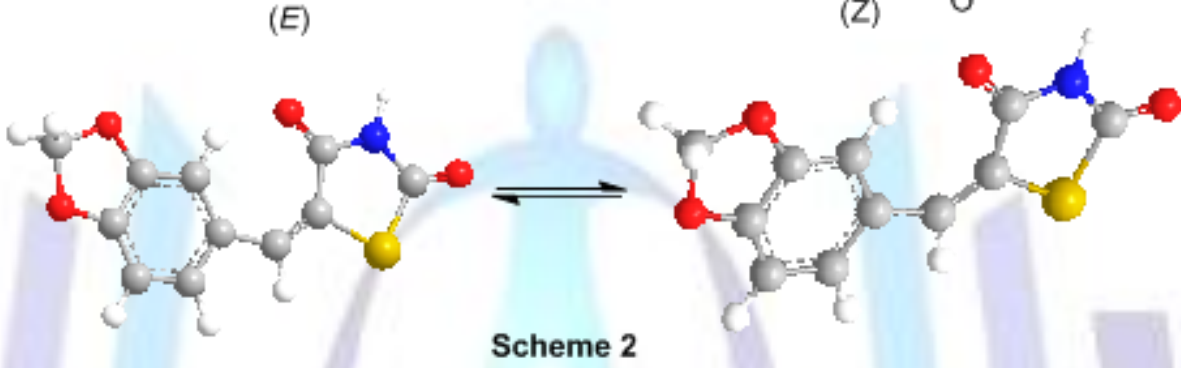

Scheme 2

Due to the lowest calculated energy for TheE-Ketoform, so,it's formis the most preferred structure for compound 3 (Scheme2 and3, table1).

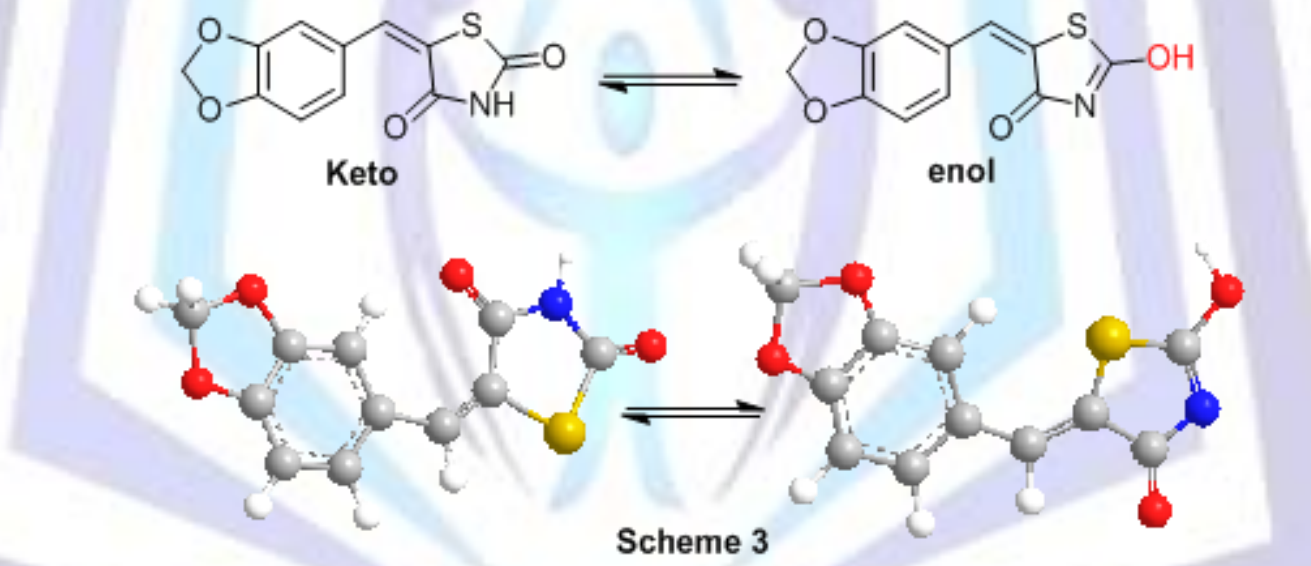

The frontier molecular orbital's (highest occupied molecular orbital, HOMO and lowest unoccupied molecular orbital, LUMO) are the most important orbitals in a molecule; these orbitals determine the way for the molecule interacts with other species. In general, the Eshowed lower HOMO energy than Z forms. This data support that, the $\boldsymbol{E}-\boldsymbol{K}$ Keto form ishighest chemical reactivity and kinetic stability form [25-28].

The total dipole moment is considering important physical quantity, it reflects the ability interaction of the molecules with the surrounding environment, the E-Ketoare highest dipole value ( 3.20 Debye), which increasing ability of interaction with the surrounding environments, and increase ability to binding with protein receptors, which increasing biological effects. The largest HOMO-LUMO gaps for $\boldsymbol{E}$-Keto form, more electrophilcity (likely to involve reactions with a nucleophile) than other forms (Table 1).

Table 1: The optimized calculations energies and reactivity descriptors of 3atHF with 6-311G basis set.

\begin{tabular}{|c|c|c|c|c|c|c|c|c|c|c|c|c|c|c|}
\hline & Form & E & Eaq & IP & $\mathrm{HF}$ & номо & LUMO & $\Delta \mathbf{G}$ & $\eta$ & S & $x$ & $\mu$ & $\omega$ & D \\
\hline \multirow{3}{*}{3} & E-Keto & -104553 & -843344 & 8.721 & -90.65 & -8.740 & -1.017 & 7.723 & 3.861 & 0.258 & -4.878 & 4.878 & 3.081 & 3.202 \\
\hline & $z$ & -104558 & -831552 & 8.696 & -96.11 & -8.696 & -0.971 & 7.725 & 3.862 & 0.258 & -4.833 & 4.833 & 3.024 & 2.681 \\
\hline & E-enol & -104557 & -834877 & 8.740 & -94.43 & -8.721 & -0.995 & 7.726 & 3.863 & 0.258 & -4.858 & 4.858 & 3.054 & 2.391 \\
\hline
\end{tabular}


E:The total energy ( $\mathrm{kcal} / \mathrm{mol})$.,Eaq: aqueous energy $(\mathrm{kcal} / \mathrm{mol}$, heat of formation + strain energy),HOMO Highest Occupied Molecular Orbital (eV), LUMO: Lowest Occupied Molecular Orbital (eV), $\boldsymbol{A G}$ : difference between HOMO and LUMO energy levels $(\mathrm{eV}), \boldsymbol{\eta}$ : Hardness $(\mathrm{eV}), \mathbf{S}$ : Softness $(\mathrm{eV}), \mathbf{X}$ : Electronegativity (eV), $\boldsymbol{\mu}$ : chemical potential(eV), $\boldsymbol{\omega}$ :Electrophilicity (eV), D: dipole moment (Deby).

\subsubsection{Global and local reactivity descriptors:}

Hartree-Fock theory has been successful to recognize the chemical reactivity and site selectivity of the molecular systems, several global and local chemical reactivity descriptors for molecules have been defined, like $\boldsymbol{S}$; softness (measures stability of molecules and chemical reactivity with direct proportional) [29] $\boldsymbol{\eta}$; hardness (reciprocal of softness), $\boldsymbol{\mu}$; chemical potential, $\boldsymbol{X}$; electronegativity (strength atom for attracting electrons to itself), $\boldsymbol{\omega}$; electrophilicity index (measuring lowering energy due to maximal flowing electron between donor and acceptor), the Fukui function and the philicity [29-34].

The E-Ketoformhas smallest hardness valueandhighestthe electrophilic capacity (Table 1), which indicating its more reactive molecularform and increasing susceptibly of nucleophilic attack on this molecule, this behavior may be explained by a large bond order for carbonyl group, exhibiting a stronger electron-attractor effect, that might be related with a localization of electronic density on its atom (Figure 2).

\subsubsection{Optimized Geometry}

the X-ray single crystal for compound3is not available till now, since, in trying to achieve better insight of the molecular structure till the crystal structures have been solved, the optimization geometry were performed in vacuo with HF quantum mechanical level using 6-311G set (Scheme 1and 2;Sup. Table 1 in supplementary material).

The benzodioxole ring was arranged in coplanar position with 2,4-thiazldinon ring, and deviation angle from stereoisomer center about $\left(\sim 133^{\circ}, 132^{\circ}\right.$ and $\left.120^{\circ}\right)$ for forms E-Keto, $Z$ and E-enol, respectively, the bond lengthsofdoublebound $\left(\mathrm{C}_{5}-\mathrm{C}_{8}\right)$ are nearly equal about $(\sim 1.3 \AA)$ for all forms (Sup. Figure (1and 2$)$ and Sup. Table 1 in supplementary material).

\subsubsection{Electrostatic potentials (ESP) and lonization potential (IP) mapped.}

The electrostatic potentials mapped (ESP) were drawn,which represents a balance between repulsive interactions of the nuclei (positively-charged) and attractive interactions for the electrons (negatively-charged). The colors toward red depict negative potential representing (high electron density area, strong attraction between the proton and the points on the molecular surface), while colors toward blue depict positive potential, and colors in between (orange, yellow, green) depict intermediate values of the potential. The most negative potential area located in $\mathrm{CO}$ group in all forms, whicharranged byE-Keto $<Z \leq E$-enol(figure 2).

The local ionization potentials (IP) were drawn (figure 2), it indicates the proportional electron removal facility around the molecule (ionization), which measure the sensitivity of a molecular zone toward electrophilic attack (reactivity). The default program value (Fixed Value: $(0.032 \mathrm{e})$; Medium Resolution), is used for the surface mapped values of the (IP) (Figure 2). The red color representing a region with highest likely attack with electrophile, and the blue regions likely attack with nucleophile (lowest electrophilic regions). The examination structures in (figure 2) showed that, the compound E-Keto formhave most electron rich around the surface of the molecule than other forms. This data suggest that, its formundergoing reaction, and occurring with higher conformation energy than other forms Zand E-enol. The examination distribution ideal charge for IP surface exhibits, the electrophile attack on surface of E-Keto form is favorable than other members, which given the red-yellow color distribution.
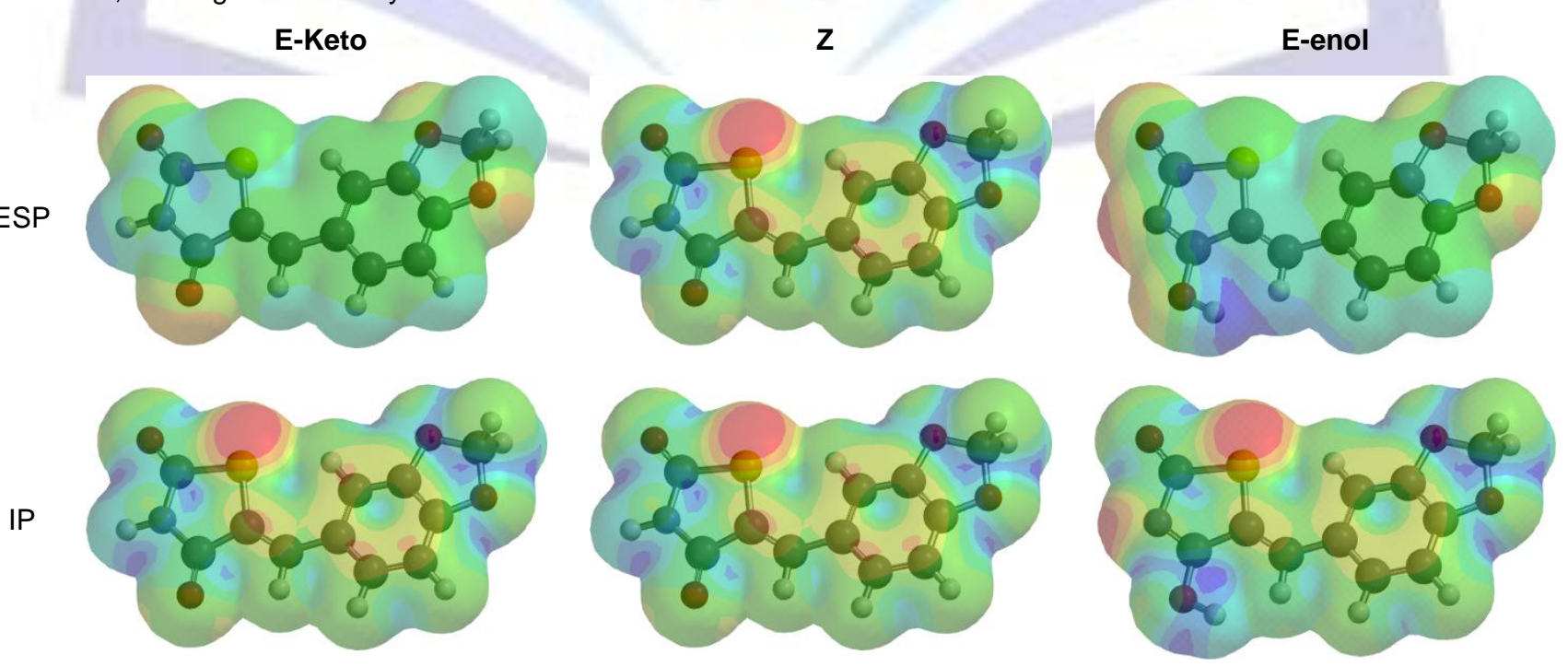

Figure. 2. The ESP and IP surfaces for most stable stereoisomer and most stable tautomer structure of 3 with $\mathrm{HF} / 6-311 \mathrm{G}$ calculations. 


\subsubsection{ADMET factorsprofiling:}

Oral bioavailability playing an important role for the development of bioactive molecules as therapeutic agents. Many potential therapeutic agents fail to reach the clinic, because of their ADMET (absorption, distribution, metabolism, elimination and toxic) factors. Therefore, a computational study for prediction of ADMET properties of the molecules were performed for reference drugs and its compounds 3, by the determination of topological polar surface area (TPSA), a calculated percent absorption (\% ABS) which was estimated by Zhao etal. equation [35] and "rule of five" formulated by Lipinski [36] which established that, chemical compound could be an orally active drug in humans, if no more than one violation of the following rule: (i) ClogP (partition coefficient between water and octanol) < 5.(ii) Number of hydrogen bond donors sites $\leq 5$.(iii) Number of hydrogen bond acceptors sites $\leq 10$.(iv) Molecular weight $<500$ and molar refractivity should be between 40-130. In addition, the total polar surface area (TPSA) is another key property linked to drug bioavailability, the passively absorbed molecules with (TPSA $>140$ ) have low oral bioavailability [37].

Table 2: Pharmacokinetic parameters important for good oral bioavailability of compounds 2-5:

\begin{tabular}{ccccccccccc}
\hline CPD & TPSA & \%ABS & Vol. & M.wt. & Logp & HBD & HBA & $\boldsymbol{V}$ & $\boldsymbol{m r}$ & LogS \\
\hline $\mathbf{3}$ & 64.63 & 86.70 & 107.25 & 393 & 2.21 & 1 & 5 & 0 & 50.49 & -3.04 \\
Pioglitazone & 68.29 & 85.43 & 171.37 & 356 & 3.29 & 1 & 5 & 0 & 55.98 & -4.62 \\
Rosiglitazone & 71.53 & 84.32 & 154.87 & 343 & 2.73 & 1 & 6 & 0 & 40.40 & -3.70 \\
Troglitazone & 84.86 & 79.72 & 197.62 & 441 & 4.94 & 2 & 6 & 0 & 40.40 & -5.90 \\
\hline
\end{tabular}

TPSA: Topological Polar surface areaA²,\%ABS:Absorption percentage, Vol: Volume (A3), M.wt.:Molecular weight, Log P: Calculated lipophilicity., LogS: Solubility parameter, HBA Number of hydrogen bond acceptor, HBD: Number of hydrogen bond donor, V: Number of violation from Lipinski's rule of five., mr: Molar Refractivity

All calculated descriptors were performed using MOE Package [38], and their results were disclosed in (Table 2). Our results revealed that, the CLogP (factor of the lipophilicity [39] was less than 5.0, the molecular weight (MW< 500), hydrogen bond acceptors (2), hydrogen bond donors (6) and molar refractivity values ranged ( 40.40-50.49), this data showedthat,its compounds fulfill Lipinski's rule.

The drug-likeliness calculated (Table 2), according to (ADME-T) algorithm [40,41], which examined the ability of compounds for transported across the intestinal epithelium, they probably have high affinity binding to the plasma proteins, and may be through the blood-brain barrier, and it necessary for ability drug transported throughout the body.

In general, No marked health effects in rodent toxicity profiles were observed, its compound $\mathbf{3}$ the compounds can be used as a good oral absorption.

\subsection{Docking studies:}

The X-ray crystal structures of ALR2 have been recognized in the PDB database [42]. The analysis of the active site for ALR2 showed that, binding site of the ALR2 can be divided into two sub-pockets, (a) catalytic pocket (also called the recognition region), (b) specificity pocket. The catalytic pocket is rather stable in all the various reported crystal structures. In contrast, the specificity pocket can adopt different conformations, adapting itself to the size of the bound ligands via movement of the loop region between Cys298 and Cys303 and the different rotameric states of the surrounding amino acid side chains, especially of Leu300, which acting as a gate-keeper between the open and closed states. Until recently, only three different conformations of the specificity pocket were known, which called by Zentgraf et al [43]. The binding pocket conformations were exemplified by the PDB structures 1PWM, which used in this study. In order to understand the binding mode for protein-ligand interactions, the docking study was carried out using MOE [38]. The crystal structure of the human ALR2 enzyme (1PWM) complexed with (ligand Fidarestat, Figure.3)asaninhibitor,was downloaded from a protein data bank PDB [44].The tested compound 3 was evaluated in silico (docking), using X-ray crystal structures of ALR2 (ID: 1PWM) [44] complexes with Fidarestat as inhibitor. The tested compound 3 docked into active sites of enzymeALR2. The active site of the enzyme was defined to include residues within a $10.0 \AA$ radius to any of the inhibitor atoms. MOE scoring function of the most stable docking model for tested compound applied to evaluate the binding affinities between the inhibitors complexes with ALR2 active site (Table 3). The complexes were energy-minimized with an MMFF94 force field [45] until the gradient convergence $0.05 \mathrm{kcal} / \mathrm{mol}$ reached. The most active compounds docked successfully into the ALR2 active site. The Dock scoring function was applied to evaluate the binding affinities between the (1PWM) and selected synthesized inhibitors (Rosiglitazone, Troglitazone and Pioglitazone). The (FIDand Rosiglitazone, Troglitazone and Pioglitazone) werere-docked into the active site of the enzyme, and then replaced it with the tested compound in order to compare the binding mode of ligand, and the tested compounds.

From (Figure3and 4; Table 3), the following results can be drawn: FID (original ligand) reveals MOE score (-81.52 $\mathrm{Kcal} / \mathrm{mol}$ ) and forms 3 hydrogen bonds with: His 110 , $\operatorname{Tyr}_{48}$ and $\operatorname{Trp}_{111}$, respectively, (Figure 3 ). Compared with (markted drugs) Rosiglitazone, Troglitazone and Pioglitazone, the compound (3) gives highest binding affinity with MOE score ($149.59 \mathrm{Kcal} / \mathrm{mol}$ ) due to forming important interaction with $\mathrm{His}_{110}, \operatorname{Tyr}_{48}, \operatorname{Trp}_{111}$ and $\operatorname{Trp}_{110}$ (Figure 4), otherdrug showed nearly binding affinity values ( 146.34, 145.39 and 142.84) for Pioglitazone, Rosiglitazone and Troglitazone and, respectively, (table 3). 
Table3: Docking energy scores $(\mathrm{kcal} / \mathrm{mol})$ derived from the MOE for new compounds 2-5:

\begin{tabular}{c|rrrrrr}
\hline Cpd. & dG & Int. & H.B. & Eele & Evdw & E-sol \\
\hline Fid. & -81.529 & 0.769102 & -77.706 & -5.52001 & -19.2262 & -81.529 \\
Pioglitazone & -146.34 & -14.0453 & -130.56 & -6.48513 & -19.7742 & -24.649 \\
Rosiglitazone & -145.39 & -35.2538 & -104.44 & -5.10474 & -11.0811 & -35.846 \\
Troglitazone & -142.84 & -37.9496 & -95.959 & -4.71776 & -22.1582 & -31.954 \\
$\mathbf{3}$ & -149.59 & -2.48743 & -104.39 & -5.57448 & -4.94787 & -29.165
\end{tabular}

d.G.: free binding energy of the ligand from a given conformer, Int.: affinity binding energy of hydrogen bond interaction with receptor, H.B.: Hydrogen bonding energy between protein and ligand.Eele: the electrostatic interaction with the receptor, Evdw: van der Waals energies between the ligand and the receptor, E-sol.: energies between the ligand and the solvent for receptor.

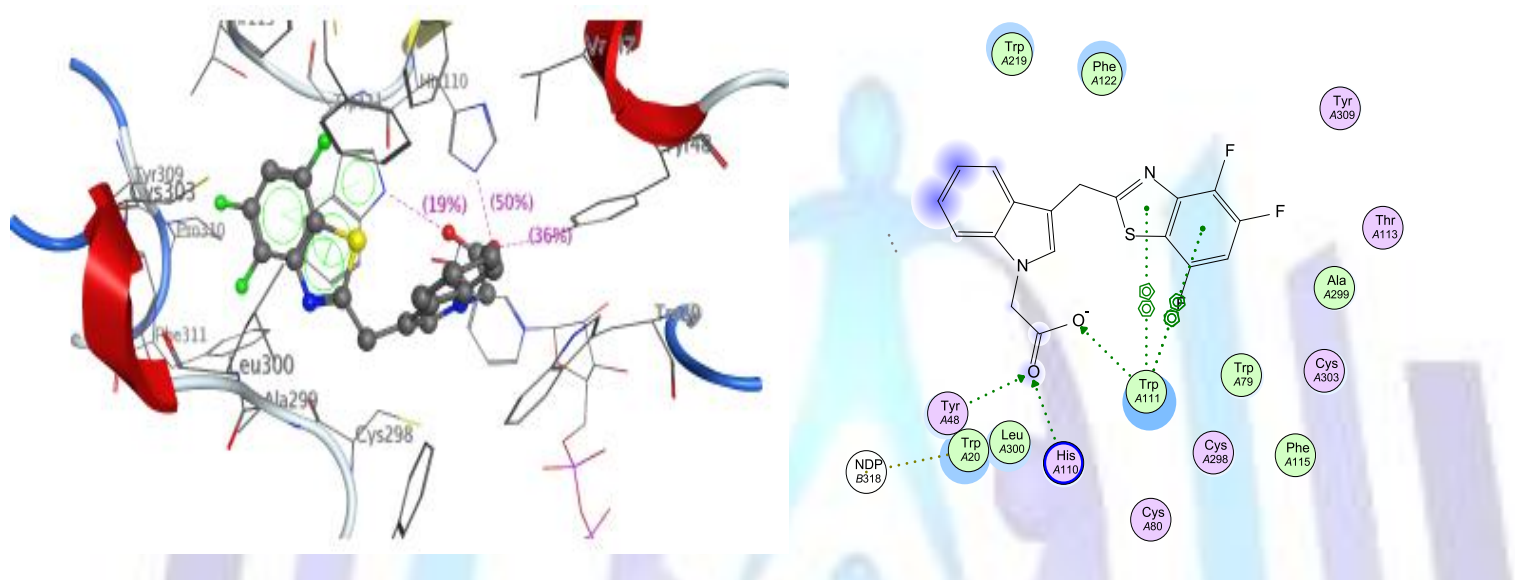

Figure 3: Interaction between ligand (FID) and binding site of ALR2 (1PWM, PDB code), which red dot lines represented hydrogen bonding interaction of ligand (Fid) with binding site. Ligand (Fid) are represented in ball and stick mode, which carbon atoms are colored in dark grey, oxygen in red, nitrogen in blue and sulfur in yellow.

The results obtained clearly reveals that, the amino acid residues close to the reference molecules Fidarestat are mostly the same as those observed in the currently synthesized compound3complex with protein (figure3 and 4). The higher binding energies and binding process interaction observed for compound3compared with the original inhibitorsindicate that, this compound $\mathbf{3}$ act as inhibitor against ALR-2 and considering suitable key intermediate for synthesis ALR-2 inhibitorwith higher potency than marketed drug.

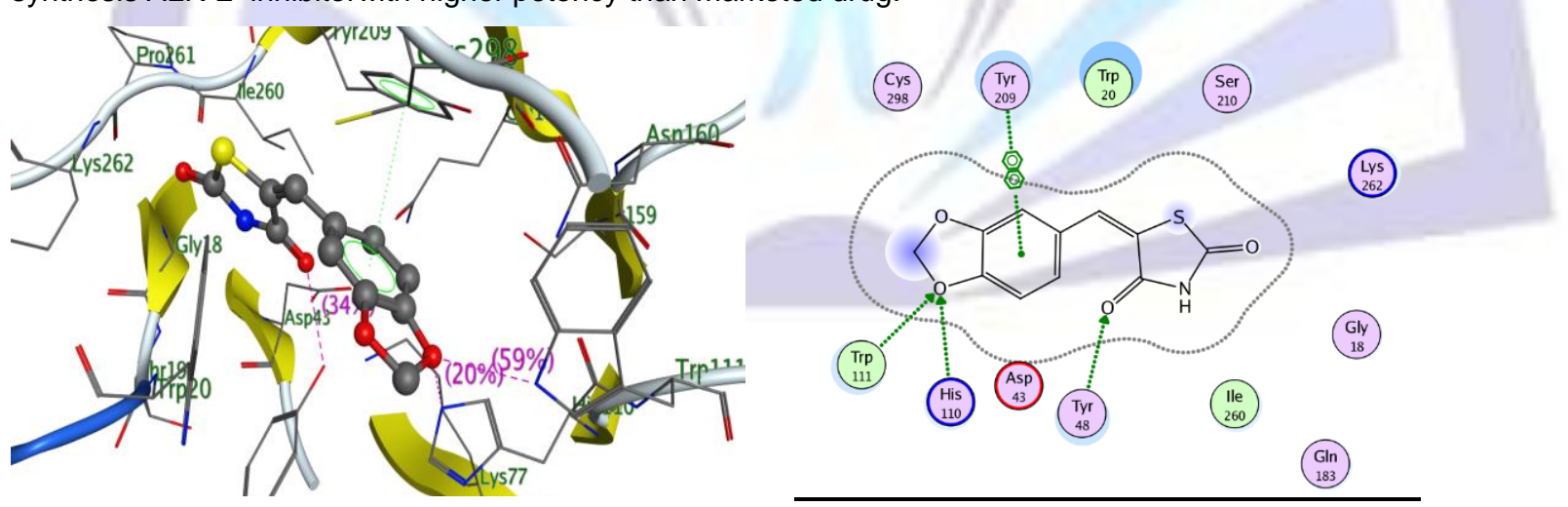

Figure 4: Interaction between ligand 3 and binding site of ALR2 (1PWM, PDB code), which red dot lines represented hydrogen bonding interaction of ligands with binding site. Ligands 3 are represented in ball and stick mode, which carbon atoms are colored in dark grey, oxygen in red, nitrogen in blue and sulfur in yellow.

\section{Conclusion}

The present work aimed to the development of novel anti-diabetes molecules containing thiazolidinedione pharmacophore. Systematic structure based virtual screening of the synthesized compound library, identified synthesized compounds as putative ALR2 binders. The results point that, the compound $\mathbf{3}$ considers suitable inhibitor against ALR2 than reference drug. 


\section{Acknowledgment:}

This research is a part of a project entitled "Design and synthesis some new drugs trying to inhibit diabetes disease in Albaha.". This project was funded by the Deanship of Scientific Research, Albaha University, KSA. The assistance of the Deanship is gratefully acknowledged.

\section{Experimental:}

\subsection{Instrumentation and materials:}

Melting points are uncorrected. IR spectra were recorded on a Shimadzu 440 infrared spectrophotometer $\left(\mathrm{U} ; \mathrm{cm}^{-1}\right)$ using the KBr technique (Shimadzu, Japan). NMR spectra were recorded on a Varian Gemini spectrometer ( $\delta$; ppm) 400 $\mathrm{MHz}$ using TMS as internal standard. Mass spectra were recorded on a Jeol-JMS-600 mass spectrometer. Micro analytical data were obtained from the Micro analytical Research Centre, Faculty of Science, Cairo University.

\subsection{Synthesis:}

\section{(E)-5-(benzo[d][1,3]dioxol-5-ylmethylene)thiazolidine-2,4-dione:}

The thiazolidinediones $(\mathbf{1} ; 0.01 \mathrm{~mol})$ in absolute ethanol $(20 \mathrm{~mL})$ containing catalytic amount $(0.5 \mathrm{gm})$, fused sodium acetatewas reacted with $(1 ; 0.01 \mathrm{~mol})$ benzodioxole carbaldehyde $(0.01 \mathrm{~mol})$ was added. The reaction mixture was heated under reflux for $3 \mathrm{~h}$. The solid product formed was collected by filtration and recrystallized from ethanol.

3: yellow crystals, yield $72 \%$, m.p. $205-07^{\circ} \mathrm{C}$. IR $\left(\mathrm{KBr}, \mathrm{cm}^{-1}\right): 3158(\mathrm{NH})$, and 1708, and $1628\left(\mathrm{C}=\mathrm{O}\right.$ thiazolidinone). ${ }^{1} \mathrm{H}$ NMR (DMSO-d $)) \delta:$ 12.47(s, $1 \mathrm{H}, \mathrm{NH}), 7.57\left(\mathrm{~s}, 1 \mathrm{H}\right.$, CHethylene),7.04-6.95 (m, 3H, aromatic), 6.01 (s, $2 \mathrm{H}$, CHdioxole); ${ }^{13} \mathrm{C}$ NMR (125 MHz) $\left(\mathrm{CDCl}_{3}\right) \delta: 167.71$ and 167.22 (CO), 149.09 (C-10), 147.96 (C-9), 131.73 (C-8), 127.02 (C-13), 125.85 (C-12), 108.94 (C-11), 108.87 (C-14), 101.93 (C-16); MS m/z (\%):250 ( $\left.\mathrm{M}^{+}+1,13.22\right)$, with a base peak at 127 (100); Anal. Calcd for $\mathrm{C}_{11} \mathrm{H}_{7} \mathrm{NO}_{4} \mathrm{~S}$ : C, 53.01; $\mathrm{H}, 2.81 ; \mathrm{N}, 5.64$. Found: $\mathrm{C}, 53.01 ; \mathrm{H}, 2.83 ; \mathrm{N}, 5.66 \%$.

\subsection{Molecular Modelling Study:}

\subsubsection{Generation of Ligand and Enzyme Structures:}

Docking study was carried out for the target compounds into (ALR2), the crystal structure of the (1PWM) complexed with (FID) was uploaded from the protein data bank PDB[44].

\subsubsection{Preparation of Small Molecule:}

All electronic structure calculations were performed using the gaussian 09 program. Geometry optimizations have been achieved using molecular orbital for Hartree-Fock functional theory with a 6-311G basis sets. The structural parameters, such as the dipole moment of the molecules, the energy of the highest occupied molecular orbital EHOMO and the lowest unoccupied molecular orbital ELUMO. The graphical representation of the molecular electrostatic potential surface (MEP or ESP), as implemented within gaussian 09 program.

\subsubsection{MOE Stepwise}

The crystal structure of the (ALR-2) with a Fid as inhibitor molecule, was used for the receptor molecule, Water and inhibitor molecules were removed, and hydrogen atoms were added. The parameters and charges assigned with MMFF94x force field. After alpha-site spheres were generated using the SITE FINDER module of MOE. The optimized 3D structures of molecules were subjected to generate different poses of ligands using triangular matcher placement method, which generating poses by aligning ligand triplets of atoms on triplets of alpha spheres representing in the receptor site points, a random triplet of alpha sphere centers is used to determine the pose during each iteration. The pose generated rescored using London dG scoring function. The poses generated were refined with MMFF94x forcefield, also, the solvation effects were treated. The Born solvation model (GB/VI) used to calculate the final energy, and the finally assigned poses assigned a score based on the free energy in $\mathrm{kcal} / \mathrm{mol}$

\section{References}

1. P. Zimmet, K. G. M. M. Alberti, J. Shaw, Nature, 2001, 414, 782.

2. S. Wild, G. Roglic, A. Green, R. Sicree, H. King, Diabetes Care, 2004 , 27, 1047.

3. P.F. Kador, Med. Res. Rev., 1988, 8, 325.

4. Diamond, J. Nature, 2003, 423, 599.

5. H. King, R. E. Aubert, W. H. Herman, Diabetes Care, 1998, 21 , 1414.

6. M. Brownlee, Nature, 2001, $414,813$.

7. S. Suzen, E. Buyukbingol, Curr. Med. Chem., 2003, 15, 1329.

8. D. Jr. Porte, M. W. Schwartz, Science, 1996, $272,699$.

9. P. F. Kador, J. H. Kinoshita, N. E. Sharpless, J. Med.Chem. 1985, 28, 841. 
10. C. Y. Nishimura, Pharmacol. Rev. 1998, $20,21$.

11. L. Costantino, G. Rastelli, G. Cignarella, P. Vianello, D. Barlocco, Exp. Opin. Ther. Patents 1997, 7, 843.

12. B. H. Wollfenbuttel, T. W. Van Haeften, Drugs 1995, 50, 263.

13. S.Miyamoto, Chem-Bio Inform. J. 2002, 2, 74.

14. S. Narayanan, Ann. Clin. Lab. Sci., 1993, 23, 148.

15. E. R. Larson, C. A. Lipinski, R. Sarges, Med. Res. Rev.1988, 8, 159.

16. L. Costantino, G. Rastelli, P. Vianello, G. Cignarella, D. Barlocco, Med. Res. Rev. 1999, $19,3$.

17. L. Costantino, G. Rastelli, M. C. Gamberoni, D. Barlocco, Exp. Opin. Ther. Patents, 2000, 10, 1245.

18. P. Alexiou, K. Pegklidou, M. Chatzopoulou, I. Nicolaou, V.J. Demopoulos, Curr. Med. Chem., 2009, $16,734$.

19. R. Maccari, R. Ottanà," 2,4-Thiazolidinedione and 2-thioxo-4-thiazolidinone derivatives as aldose reductase inhibitors in the search for drugs to prevent long-term diabetes complications. in: M. Stefek (Ed.), Advances in Molecular Mechanisms and Pharmacology of Diabetic Complications." Transworld Research Network, Kerala, 2010, pp. 219-245.

20. D. E. Moller, Nature, 2001, 414, 821.

21. M. Strumvoll, H-U. Haring, Ann. Med., 2002, 34, 217.

22. T. M. Wilson, P.J. Brown, D.D. Sternbach, B.R. Henke, J. Med. Chem., 2000,43, 527.

23. L.Werner, M. T. Travaglini , 2001,21, 1082.

24. M.J. Frisch, et al., Gaussian 09, revision A.02, Gaussian, Inc., Wallingford, CT, 2009.

25. S. Sagdinc, B. Koksoy, F. Kandemirli, S.H. Bayari, J. Mol. Struct. 2009, 63, 917.

26. A. Rauk, Orbital Interaction Theory of Organic Chemistry, 2nd ed., Wiley

27. Interscience, New York, (2001), pp. 86.

28. A. Streitwieser Jr., Molecular Orbital Theory for Organic Chemists, Wiley New York, 1961.

29. I.Fleming,. (Frontier Orbitals and Organic Chemical Reactions), John Wiley and Sons, Academic Press, New York 1976.

30. R. G.Parr,P. K. Chattaraj, J. Am. Chem. Soc. 1991,113, 1854.

31. R. G.Parr, L. V.Szentpaly,S. J. Liu, Am. Chem. Soc. 1999,121, 1922.

32. P. K.Chattaraj, B.Maiti, U. Sarkar, J. Phys. Chem. A 2003,107 , 4973.

33. R. G.Parr, R. A.Donnelly, M.Levy, W. E. Palke, J. Chem. Phys. 1978, 68 , 801.

34. R. G. Parr, R. G. Pearson, J. Am. Chem. Soc. 1983,105, 7512.

35. Y. Zhao, M.H.Abraham,J. Lee,A.Hersey, N.Ch.Luscombe, G. Beck, B.Sherborne, I.Cooper, Pharm. Res. 2002,19 , 1446.

36. C.A.Lipinski,F. Lombardo, B.W.Dominy, P.J.Feeney,; Adv. Drug. Delivery Rev. 1997,23 , 3.

37. D.E.Clark, S.D.Pickett, Drug Discov. Today, 2000,5 , 49.

38. Chemical Computing Group. Inc, MOE, 2009, 10.

39. S.A.Wildman, G.M.Crippen, J. Chem. Inf. Comput. Sci. 1999,39, 868.

40. Pharma Algorithms (Web Edition) 5 (2009).

41. T.L. Moda, L.G. Torres, A.E. Carrara, A.D. Andricopulo, PK/DB: database for pharmacokinetic properties and predictive in silico ADME models. Bioinformatics 24 (2008) 2270.

42. H. M. Berman, J.Westbrook, Z.Feng,G. Gilliland, T. N.Bhat, H.Weissig, I. N.Shindyalov, P. E.Bourne, Nucleic Acids Res. 2000, 28, 235-242.

43. M.Zentgraf,H. Steuber, C Koch,C. La Motta, S.Sartini, C. A.Sotriffer, G. Klebe, Angew. Chem., Int. Ed. Engl.," How Reliable Are Current Docking Approaches for Structure-Based Drug Design? Lessons from Aldose Reductase', 2007, 46, 3575-3578.

44. O.El-Kabbani,C. Darmanin, T. R.Schneider, I.Hazemann, F.Ruiz,; M.Oka,A.Joachimiak, C.Schulze-Briese, T.Tomizaki, A. MitschlerPodjarny, A Proteins, 2004 , 55, 805-813.

45. T.A. Halgren, J. Comput. Chem. 1996,17, 490 


\section{Supplementary material}

Sup. Table 1: Optimized geometrical parameters of compound3 using HF with 6-311G basis set.

\begin{tabular}{|c|c|c|c|c|c|c|c|c|c|c|c|c|c|c|c|c|c|c|c|c|}
\hline \multicolumn{9}{|c|}{ Bond length } & \multicolumn{12}{|c|}{ Bond Angel } \\
\hline \multicolumn{3}{|c|}{ E-keto } & \multicolumn{3}{|c|}{$\mathbf{Z}$} & \multicolumn{3}{|c|}{ E-enole } & \multicolumn{4}{|c|}{ E-Keto } & \multicolumn{4}{|c|}{$\mathbf{Z}$} & \multicolumn{4}{|c|}{ E-enole } \\
\hline$C(1)$ & $\mathrm{C}(9)$ & $C(10)$ & $\mathrm{C}(13)$ & $C(12)$ & 1.376 & $C(10)$ & $\mathrm{C}(9)$ & 1.381 & $\mathrm{C}(11)$ & $C(10)$ & $\mathrm{C}(9)$ & 120.123 & $O(9)$ & $C(13)$ & $\mathrm{C}(12)$ & 112.439 & $C(11)$ & $\mathrm{C}(10)$ & $\mathrm{C}(9)$ & 121.741 \\
\hline$C(11)$ & $C(10)$ & $C(11)$ & $\mathrm{O}(9)$ & $C(13)$ & 1.360 & $C(11)$ & $C(10)$ & 1.368 & $\mathrm{O}(17)$ & $C(10)$ & $\mathrm{C}(9)$ & 111.699 & $C(14)$ & $C(13)$ & $\mathrm{O}(9)$ & 125.783 & $\mathrm{O}(17)$ & $C(10)$ & $C(9)$ & 109.571 \\
\hline $\mathrm{O}(17)$ & $C(10)$ & $\mathrm{O}(17)$ & $\mathrm{C}(14)$ & $C(13)$ & 1.379 & $\mathrm{O}(17)$ & $C(10)$ & 1.379 & $C(14)$ & $\mathrm{C}(9)$ & $C(10)$ & 121.436 & $\mathrm{O}(11)$ & $C(12)$ & $C(13)$ & 112.438 & $C(14)$ & $C(9)$ & $C(10)$ & 122.612 \\
\hline$C(14)$ & $\mathrm{C}(9)$ & $C(14)$ & $\mathrm{O}(11)$ & $C(12)$ & 1.360 & $C(14)$ & $\mathrm{C}(9)$ & 1.363 & $\mathrm{O}(15)$ & $\mathrm{C}(9)$ & $C(10)$ & 110.983 & $C(17)$ & $C(12)$ & $\mathrm{O}(11)$ & 125.783 & $\mathrm{O}(15)$ & $C(9)$ & $C(10)$ & 109.384 \\
\hline $\mathrm{O}(15)$ & $\mathrm{C}(9)$ & $\mathrm{O}(15)$ & $C(17)$ & $C(12)$ & 1.379 & $\mathrm{O}(15)$ & $\mathrm{C}(9)$ & 1.386 & $C(12)$ & $C(11)$ & $C(10)$ & 117.941 & $C(15)$ & $C(14)$ & $C(13)$ & 117.675 & $\mathrm{C}(12)$ & $C(11)$ & $C(10)$ & 116.602 \\
\hline$C(12)$ & $C(11)$ & $\mathrm{C}(12)$ & $C(15)$ & $C(14)$ & 1.398 & $C(12)$ & $C(11)$ & 1.395 & $C(13)$ & $C(14)$ & $\mathrm{C}(9)$ & 120.396 & $C(16)$ & $C(17)$ & $\mathrm{C}(12)$ & 117.675 & $C(13)$ & $C(14)$ & $\mathrm{C}(9)$ & 117.322 \\
\hline$C(13)$ & $C(14)$ & $C(13)$ & $C(16)$ & $C(17)$ & 1.398 & $C(13)$ & $C(14)$ & 1.41 & $C(16)$ & $\mathrm{O}(17)$ & $C(10)$ & 107.209 & $C(10)$ & $\mathrm{O}(9)$ & $C(13)$ & 100.795 & $C(16)$ & $\mathrm{O}(17)$ & $C(10)$ & 107.866 \\
\hline$C(16)$ & $\mathrm{O}(17)$ & $C(16)$ & $C(10)$ & $\mathrm{O}(9)$ & 1.443 & $C(16)$ & $\mathrm{O}(17)$ & 1.449 & $C(8)$ & $C(13)$ & $C(12)$ & 117.529 & $C(8)$ & $C(16)$ & $\mathrm{C}(15)$ & 119.727 & $\mathrm{C}(8)$ & $C(13)$ & $C(12)$ & 116.669 \\
\hline$C(8)$ & $C(13)$ & $C(8)$ & $C(8)$ & $C(16)$ & 1.337 & $C(8)$ & $C(13)$ & 1.463 & $C(3)$ & $C(8)$ & $C(13)$ & 133.408 & $C(5)$ & $C(8)$ & $C(16)$ & 120 & $C(3)$ & $C(8)$ & $C(13)$ & 132.732 \\
\hline $\mathrm{C}(3)$ & $C(8)$ & $C(3)$ & $\mathrm{C}(5)$ & $C(8)$ & 1.337 & $C(3)$ & $C(8)$ & 1.329 & $S(2)$ & $C(3)$ & $C(8)$ & 129.222 & $S(1)$ & $C(5)$ & $C(8)$ & 128.172 & $\mathrm{~S}(2)$ & $C(3)$ & $C(8)$ & 129.849 \\
\hline $\mathrm{S}(2)$ & $C(3)$ & $\mathrm{S}(2)$ & $S(1)$ & $\mathrm{C}(5)$ & 1.808 & $\mathrm{~S}(2)$ & $C(3)$ & 1.832 & $\mathrm{C}(4)$ & $C(3)$ & $\mathrm{S}(2)$ & 108.286 & $C(4)$ & $C(5)$ & $S(1)$ & 103.656 & $C(4)$ & $C(3)$ & $S(2)$ & 108.412 \\
\hline $\mathrm{C}(4)$ & $C(3)$ & $C(4)$ & $\mathrm{C}(4)$ & $C(5)$ & 1.523 & $C(4)$ & $C(3)$ & 1.496 & $C(1)$ & $\mathrm{S}(2)$ & $C(3)$ & 96.463 & $C(2)$ & $S(1)$ & $C(5)$ & 93.385 & $C(1)$ & $\mathrm{S}(2)$ & $C(3)$ & 86.68 \\
\hline$C(1)$ & $\mathrm{S}(2)$ & $C(1)$ & $\mathrm{C}(2)$ & $S(1)$ & 1.808 & $C(1)$ & $\mathrm{S}(2)$ & 1.835 & $N(5)$ & $C(4)$ & $\mathrm{C}(3)$ & 111.006 & $N(3)$ & $C(4)$ & $C(5)$ & 107.344 & $\mathrm{~N}(5)$ & $C(4)$ & $C(3)$ & 113.175 \\
\hline$N(5)$ & $C(4)$ & $\mathrm{N}(5)$ & $\mathrm{N}(3)$ & $C(4)$ & 1.465 & $N(5)$ & $\mathrm{C}(4)$ & 1.404 & $\mathrm{O}(6)$ & $C(1)$ & $\mathrm{S}(2)$ & 121.28 & $\mathrm{O}(6)$ & $C(2)$ & $S(1)$ & 126.133 & $\mathrm{O}(6)$ & $C(1)$ & $\mathrm{S}(2)$ & 119.359 \\
\hline $\mathrm{O}(6)$ & $C(1)$ & $\mathrm{O}(6)$ & $\mathrm{O}(6)$ & $C(2)$ & 1.208 & $\mathrm{O}(6)$ & $C(1)$ & 1.328 & $\mathrm{O}(7)$ & $C(4)$ & $\mathrm{C}(3)$ & 125.838 & $\mathrm{H}(22)$ & $C(14)$ & $C(13)$ & 121.163 & $\mathrm{O}(7)$ & $C(4)$ & $C(3)$ & 123.107 \\
\hline $\mathrm{O}(7)$ & $C(4)$ & $\mathrm{O}(7)$ & $\mathrm{O}(7)$ & $C(4)$ & 1.208 & $\mathrm{O}(7)$ & $\mathrm{C}(4)$ & 1.211 & & & & & $H(23)$ & $C(15)$ & $C(14)$ & 119.727 & $\mathrm{H}(20)$ & $C(11)$ & $C(10)$ & 121.5 \\
\hline $\mathrm{H}(20)$ & $C(11)$ & $\mathrm{H}(20)$ & $\mathrm{H}(22)$ & $C(14)$ & 1.100 & $H(20)$ & $C(11)$ & 1.07 & & & & & $\mathrm{H}(24)$ & $C(17)$ & $\mathrm{C}(12)$ & 121.162 & $\mathrm{H}(21)$ & $C(12)$ & $C(11)$ & 118.657 \\
\hline $\mathrm{H}(21)$ & $C(12)$ & $H(21)$ & $\mathrm{H}(23)$ & $C(15)$ & 1.100 & $H(21)$ & $\mathrm{C}(12)$ & 1.072 & & & & & $H(19)$ & $\mathrm{C}(8)$ & $C(5)$ & 120 & $\mathrm{H}(22)$ & $C(14)$ & $C(9)$ & 119.618 \\
\hline $\mathrm{H}(22)$ & $C(14)$ & $\mathrm{H}(22)$ & $\mathrm{H}(24)$ & $C(17)$ & 1.100 & $H(22)$ & $C(14)$ & 1.067 & & & & & $H(18)$ & $\mathrm{N}(3)$ & $C(2)$ & 126.463 & $H(19)$ & $C(8)$ & $C(3)$ & 112.661 \\
\hline $\mathrm{H}(19)$ & $C(8)$ & $H(19)$ & $\mathrm{H}(19)$ & $C(8)$ & 1.100 & $H(19)$ & $\mathrm{C}(8)$ & 1.076 & & & & & $\mathrm{H}(20)$ & $C(10)$ & $\mathrm{O}(9)$ & 108.426 & $\mathrm{H}(23)$ & $C(16)$ & $\mathrm{O}(15)$ & 109.695 \\
\hline $\mathrm{H}(23)$ & $C(16)$ & $\mathrm{H}(23)$ & $H(18)$ & $\mathrm{N}(3)$ & 1.012 & $H(23)$ & $C(16)$ & 1.073 & & & & & $H(21)$ & $C(10)$ & $\mathrm{O}(9)$ & 107.1 & $\mathrm{H}(24)$ & $C(16)$ & $\mathrm{O}(15)$ & 109.695 \\
\hline $\mathrm{H}(24)$ & $C(16)$ & $\mathrm{H}(24)$ & $\mathrm{H}(20)$ & $C(10)$ & 1.113 & $\mathrm{H}(24)$ & $\mathrm{C}(16)$ & 1.073 & & & & & & & & & $H(18)$ & $\mathrm{O}(6)$ & $C(1)$ & 117.249 \\
\hline$H(18)$ & $\mathrm{O}(6)$ & $H(18)$ & $\mathrm{H}(21)$ & $C(10)$ & 1.113 & $H(18)$ & $\mathrm{O}(6)$ & 0.951 & & & & & & & & & & & & \\
\hline
\end{tabular}

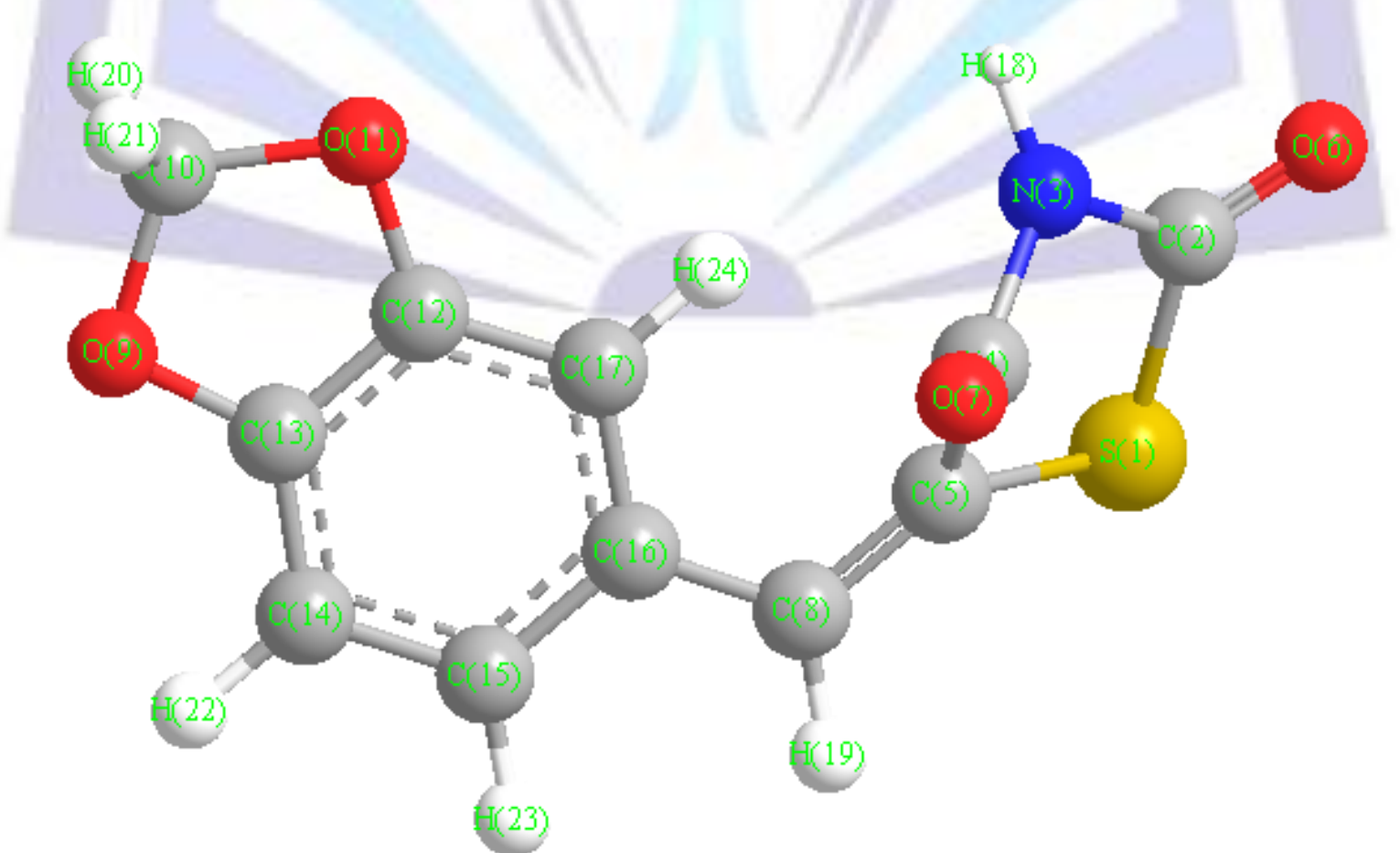

Sup. Figure1. Numbering compound E-Keto and $Z$ form according to program representing as Ball and stick. 


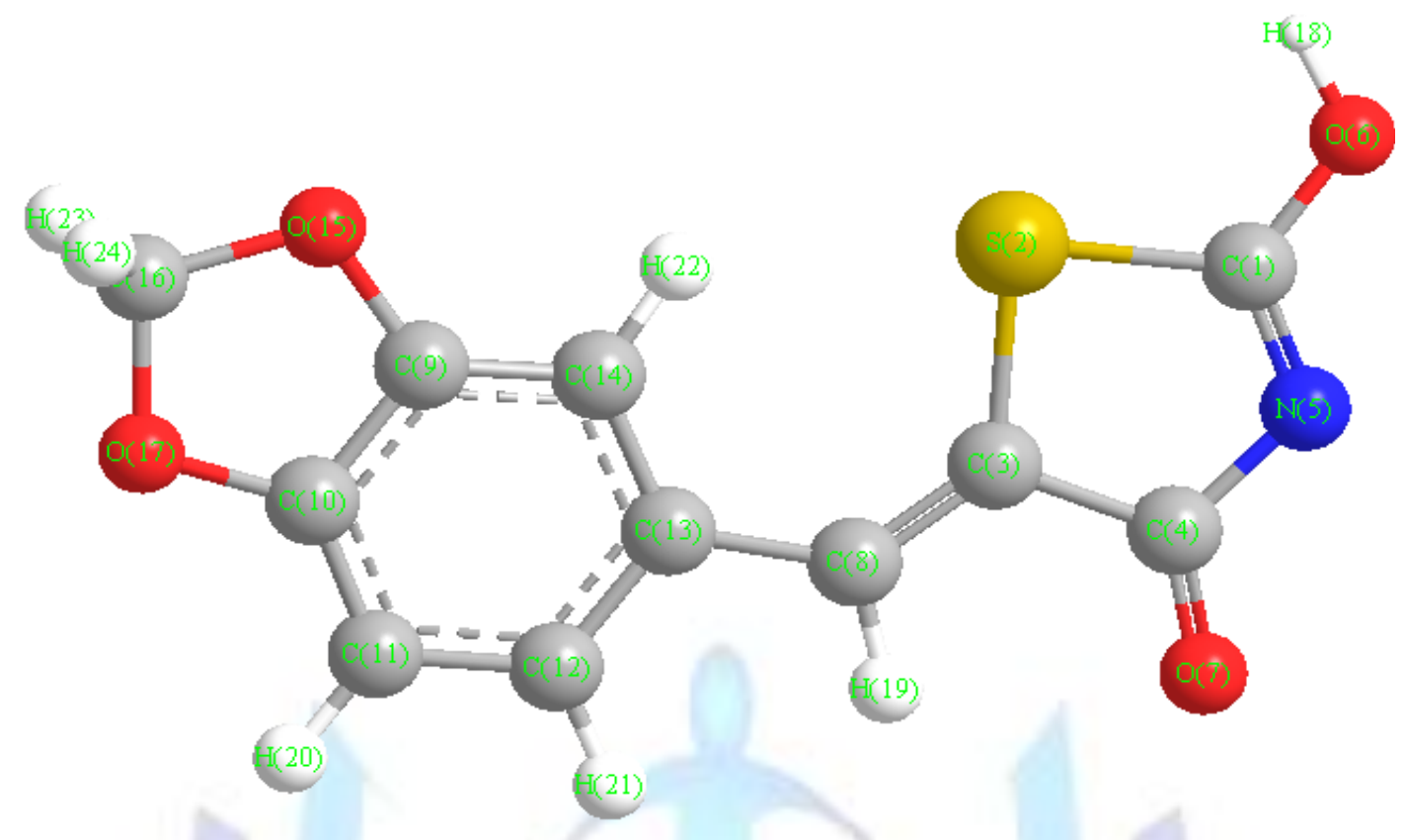

Sup. Figure2. Numbering compound E-enol according to program representing as Ball and stick.

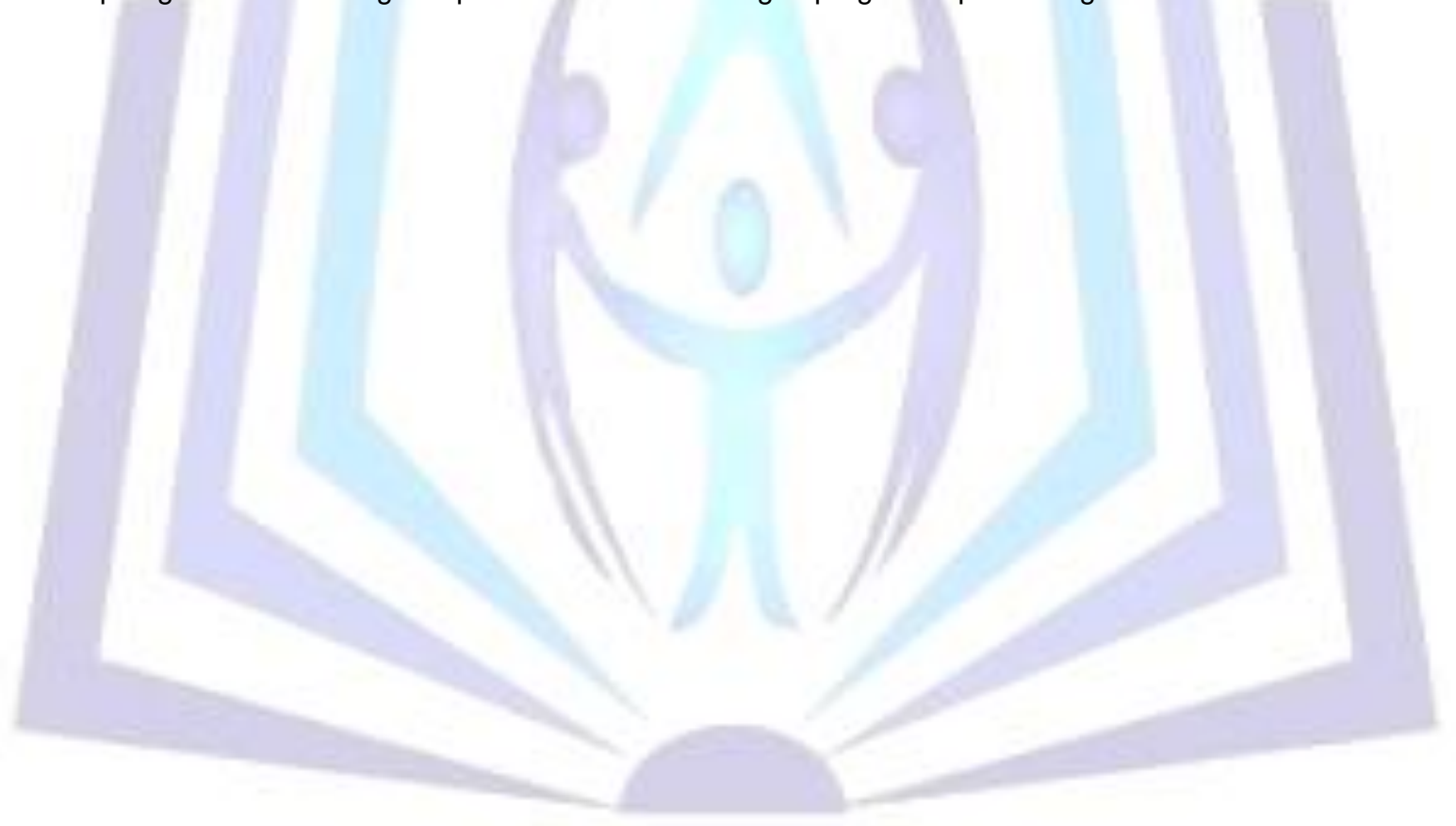

